\title{
Gram per Milliliter per Gram
}

National Cancer Institute

\section{Source}

National Cancer Institute. Gram per Milliliter per Gram. NCI Thesaurus. Code C119361.

A unit of concentration equal to grams per milliliter, divided by grams. 